\title{
Effects of early treatment of maxillary incisor crowding by using two bands and four brackets $(2 \times 4)$ mechanotherapy
}

\author{
Toshiya Endo ${ }^{1)}$, Yoshiko Mizutani ${ }^{2}$, Rieko Ozoe ${ }^{3)}$, \\ Mifumi Kubota ${ }^{1)}$ and Shohachi Shimooka ${ }^{4)}$ \\ 1) Orthodontics, Nippon Dental University Hospital at Niigata, \\ 3) Pediatric Dentistry, Nippon Dental University Hospital at Niigata, \\ 4) Department of Pediatric Dentistry, Nippon Dental University School of Dentistry at Niigata \\ 1-8 Hamaura-cho, Niigata 951-8580, JAPAN \\ 2) Meike Dental Clinic \\ 2-3-17 Meike, Niigata 950-0941, JAPAN
}

\begin{abstract}
The purpose of the present study was to investigate effects of early treatment of maxillary incisor crowding on anteroposterior skeletal and dental changes. Treatment group comprised 17 patients with maxillary incisor crowding treated with the two bands and four brackets $(2 \times 4)$ mechanotherapy, and with an initial mean age of 8 years and 10 months. Control group consisted of 17 patients with the same type of malocclusion as the treatment group and with an initial mean age of 8 years and 7 months. Lateral cephalograms in the treatment group were obtained at three time periods: T1, at the start of the $2 \times 4$ mechanotherapy; T2, at the end of the $2 \times 4$ mechanotherapy; T3, at the end of posttreatment observation. In the control group, lateral cephalograms were obtained at two time periods: T1, at the start of observation; T3, at the end of observation. Ten linear and 10 angular measurements were made for each cephalogram and the cephalometric data obtained were analysed statistically.

The significantly large retroclination of the mandibular incisors was found at $\mathrm{T} 1$ in both groups compared with Japanese norms, resulting in the obtuseness of the interincisal angle. The resolution of maxillary incisor crowding during T1-T2 produced the retrusive movement of maxillary central incisor tips and the retroclination of mandibular incisors. There were no statistically significant differences for the T1-T3 changes in any linear and angular measurements between both groups. The mandibular incisors were, however, inclined labially during T1-T3 in the treatment group, which were, on the contrary, inclined lingually in the control group. These results suggested that the resolution of maxillary incisor crowding mostly produce the anteroposterior dental effects, and that its effect on the correction of the retroclination of mandibular incisors which was observed at the start of the $2 \times 4$ mechanotherapy was not so significant.
\end{abstract}

\section{Introduction}

Maxillary incisor crowding in the mixed dentition stage of development is one of the most frequent form of malocclusion. However, almost the previous studies have been focused mainly on mandibular

Received on September 29, 2003

Accepted on December 8, 2003
Key words

Dental change,

Maxillary incisor crowding,

Skeletal change,

Two bands and four brackets mechanotherapy 
Table 1 Mean ages and mean treatment/observation periods

\begin{tabular}{cccccccc}
\hline & \multicolumn{4}{c}{ Mean Age } & & \multicolumn{2}{c}{ Mean treatment/observation period } \\
\cline { 2 - 3 } & $\mathrm{T} 1$ & $\mathrm{~T} 2$ & $\mathrm{~T} 3$ & & $\mathrm{~T} 1-\mathrm{T} 2$ & $\mathrm{~T} 2-\mathrm{T} 3$ & $\mathrm{~T} 1-\mathrm{T} 3$ \\
\hline $\begin{array}{c}\text { Treatment group } \\
(\mathrm{n}=17)\end{array}$ & $8 \mathrm{y} 10 \mathrm{mo} \pm 10 \mathrm{mo}$ & $9 \mathrm{y} 9 \mathrm{mo} \pm 9 \mathrm{mo}$ & $12 \mathrm{y} 0 \mathrm{mo} \pm 1 \mathrm{y} 0 \mathrm{mo}$ & & $12 \mathrm{mo} \pm 8 \mathrm{mo}$ & $2 \mathrm{y} 3 \mathrm{mo} \pm 9 \mathrm{mo}$ & $3 \mathrm{y} 3 \mathrm{mo} \pm 9 \mathrm{mo}$ \\
$\begin{array}{c}\text { Control group } \\
(\mathrm{n}=17)\end{array}$ & $8 \mathrm{y} 10 \mathrm{mo} \pm 7 \mathrm{mo}$ & - & $11 \mathrm{y} 10 \mathrm{mo} \pm 11 \mathrm{mo}$ & & - & - & $2 \mathrm{y} 11 \mathrm{mo} \pm 11 \mathrm{mo}$ \\
\hline
\end{tabular}

occlusion, Norderval et al. ${ }^{5}$ revealed the sagittal jaw relationship and mandibular plane angles to be significantly greater. Sakuda et al. ${ }^{6}$ ) examined the relationship between craniofacial morphology and increased crowding between the ages of 12 and 17 years, and verified that with increasing the mandibular incisor crowding, the degree of proclination of the maxillary central incisors, the intermolar angle and the maxillary length decreased, while the vertical growth in maxillary posterior segments increased. Rönnerman and Thilander ${ }^{7)}$ investigated the relationship between the craniofacial morphology and dental development in children with and without crowding, and found children with crowding had the more retrognathic maxilla and mandible, the shorter and narrower jaws, and the greater mesiodistal tooth width than those without crowding. In investigating the craniofacial morphology of cases with crowded mandibular anterior teeth compared with those with spaced mandibular anterior teeth, Leighton and Hunter $^{8)}$ found that crowded cases had the larger mandibular and occlusal plane angles, the shorter posterior face height and mandibular body, and the more retrusive mandibular incisors and symphysis. Berg $^{9)}$ revealed the smaller articulare-pogonion dimension and SNB angle in children with crowding when compared to those with normal occlusion. These studies have suggested that the mandibular anterior crowding is likely to be associated with anteroposterior skeletal and dental discrapancies.

The resolution of maxillary incisor crowding in the mixed dentition has been made by arch length preservation with lingual arch, maxillary arch expansion with Quad helix, incisor alignment with two bands and four brackets $(2 \times 4)$ mechanotherapy, serial extraction, and so on. However, the effect of the resolution of maxillary incisor crowding in the mixed dentition on the craniofacial development does not seem to have been studied. The purpose of the present study was to investigate effects of early treatment of maxillary incisor crowding on anteroposterior skeletal and dental changes.

\section{Materials and methods}

\section{Subjects and materials}

Treatment group comprised 17 consecutive Japanese patients ( 10 boys and 7 girls) with maxillary incisor crowding and with an initial mean age of 8 years and 10 months. The maxillary incisors were aligned with the $2 \times 4$ mechanotherapy. The mean age at the end of the $2 \times 4$ mechanotherapy was 9 years and 9 months. After the alignment, the observation was made until the completion of the permanent dentition at the mean age of 12 years (Table 1).

Control group consisted of 17 consecutive Japanese patients ( 4 boys and 13 girls) with the same type of malocclusion as the treatment group and with an initial mean age of 8 years and 10 months. Patients in the control group didn't have any orthodontic treatment except the observation until the completion of the permanent dentition at the mean age of 11 years and 10 months (Table 1).

All the patients in the treatment and control groups attended the Pediatric and Orthodontic Clinic, Nippon Dental University Hospital at Niigata. Informed consent was obtained from all the patients and their parents in both groups. The selection criteria in the treatment and control groups were based on the mixed dentition at Hellman's dental age III A, Angle class I occlusion, fair shape of dental arches, no congenitally missing teeth excluding third molars, no previous orthodontic or prosthodontic treatments, and acceptable cooperation.

The materials consisted of lateral cephalograms in the treatment and control groups. In the treatment group, lateral cephalograms were obtained at three time periods: T1, at the start of the $2 \times 4$ mechanotherapy; T2, at the end of the $2 \times 4$ mechanotherapy; $\mathrm{T} 3$, at the end of posttreatment observation. In the 


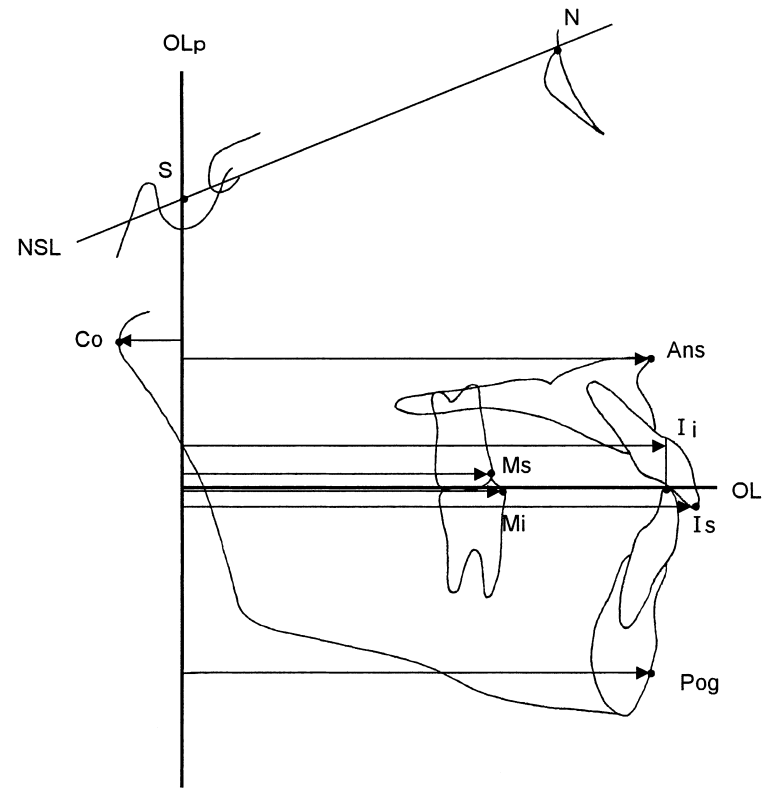

Fig. 1 Measuring points for linear measurements The registration line (NSL) and reference grid (OL and OLp) are shown.

control group, lateral cephalograms were obtained at two time periods: T1, at the start of observation; T3, at the end of observation.

\section{Cephalometric analysis}

Each lateral cephalogram at T1, T2 and T3 in the treatment group, and at $\mathrm{T} 1$ and $\mathrm{T} 3$ in the control group were traced on the acetate tracing film by a single investigator (R.O.). A cephalometric analysis of anteroposterior skeletal and dental changes occurring during the treatment (observation) period was made according to Pancherz's analyses ${ }^{10)}$, and his modified reference system for superimposing cephalograms was applied. Two reference points, 2 reference lines and 7 measuring points used in the present study are shown in Fig. 1. For all the linear measurements, the occlusal line (OL) and the occlusal line perpendiculare (OLp) from the cephalogram at T1 were used as a reference grid. The grid was transferred from the initial tracing to the following tracings at $\mathrm{T} 2$ and $\mathrm{T} 3$ in the treatment group (at T3 in the control group) by superimposing the tracings on the nasion-sella line (NSL) with sella (S) as a registration point. All linear measurements were made parallel to OL and perpendicular to OLp, and to the nearest $0.5 \mathrm{~mm}$. The analyses comprised the following measurements (Fig. 1).

1. Is/OLp minus Ii/OLp-overjet.
2. Ms/OLp minus Mi/OLp-molar relation (a positive value indicates a distal relation; a negative value indicates a mesial relation).

Skeletal measuring points

3. Ans/OLp - position of the maxillary base.

4. Pog/OLp - position of the mandibular base.

5. Co/OLp-position of the condylar position.

6. Pog/OLp $+\mathrm{Co} / \mathrm{OLp}$ - mandibular length.

Dental measuring points

7. Is/OLp - position of the maxillary central incisor.

8. Ii/OLp-position of the mandibular central incisor.

9. Ms/OLp-position of the maxillary permanent first molar.

10. $\mathrm{Mi} /$ OLp - position of the mandibular permanent first molar.

Changes of each measuring point in relation to OLp were evaluated by calculating the difference (d) in landmark position. Changes of measurements 3 to 6 demonstrate skeletal changes, while changes of measurements 7 to 10 demonstrate a total of skeletal and dental changes. Measurements for dental changes within the maxilla and within the mandible were made as follows.

11. Is/OLp (d) minus Ans/OLp (d) - Change in position of the maxillary central incisor within the maxilla.

12. Ii/OLp (d) minus Pog/OLp (d) - Change in position of the mandibular central incisor within the mandible.

13. Ms/OLp (d) minus Ans/OLp (d) - Change in position of the maxillary permanent first molar within the maxilla.

14. Mi/OLp (d) minus Pog/OLp (d) - Change in position of the mandibular permanent first molar within the mandible.

The cephalometric changes occurring during the mean treatment period of 12 months (T1-T2) in the treatment group were compared with the interpolated changes of the 12 months of the observation period in the control group (Table 1). The monthly increments were calculated and multiplied with the treatment period of 12 months to establish values for the interpolated changes in the control group. This comparison is based on no significant differences for the T1-T3 changes in any measurements between two groups.

Additional cephalometric analyses for the craniofacial morphology were performed on each cephalogram in the treatment and control groups 
according to Iizuka's analyses ${ }^{11)}$. Ten angular measurements were selected for quantitative evaluation of craniofacial morphology as shown in Fig. 2. These angular measurements were made to the nearest 0.5 degree.

\section{Statistical analysis}

All statistical analyses were performed by the StatMate III statistical program (ATMS Co., Ltd., Tokyo). Means and standard deviations, isolated according to gender and then pooled together, were calculated for each measurement at T1, T2 and T3 in the treatment and control groups. The Student's $t$-test or Welch's $t$-test was used to reveal any statistically significant differences for the linear and angular measurements at $\mathrm{T} 1$ and $\mathrm{T} 3$ between the treatment and control groups, and for the angular measurements at $\mathrm{T} 1, \mathrm{~T} 2$ and $\mathrm{T} 3$ in the treatment and control groups compared with the reference sample with Japanese normal occlusion, after a test for the homogeneity of the variances.

In addition, the calculation was made for means and standard deviations for cephalometric changes occurring during the $2 \times 4$ mechanotherapy (T1$\mathrm{T} 2$ ), the posttreatment observation (T2-T3) and the overall treatment periods (T1-T3) in the treatment group, and during the overall treatment (observation) period (T1-T3) in the control group. Statistically significant changes during each periods, and significant differences for the T1-T2 and T1-T3 changes in each measurement between the treatment and control groups were, also, evaluated by Student's $t$ test or Welch's $t$-test after a test for the homogeneity of the variances.

\section{Method error}

For assessment of method error, 30 randomly selected cephalograms were retraced and remeasured by the same examiner after a period of one month. Method error in locating, superimposing and measuring different landmarks was assessed with the Dahlberg formula $\pm \sqrt{ } z^{2} \neq n$, where $d$ is the difference between the two registrations of a pair and $n$ is the number of double registrations ${ }^{12)}$. Method error did not exceed \pm 0.4 degree or $\pm 0.3 \mathrm{~mm}$, which was acceptable in the present study.

\section{Results}

The analyses for each measurement isolated according to gender showed no significant sexual dimorphism

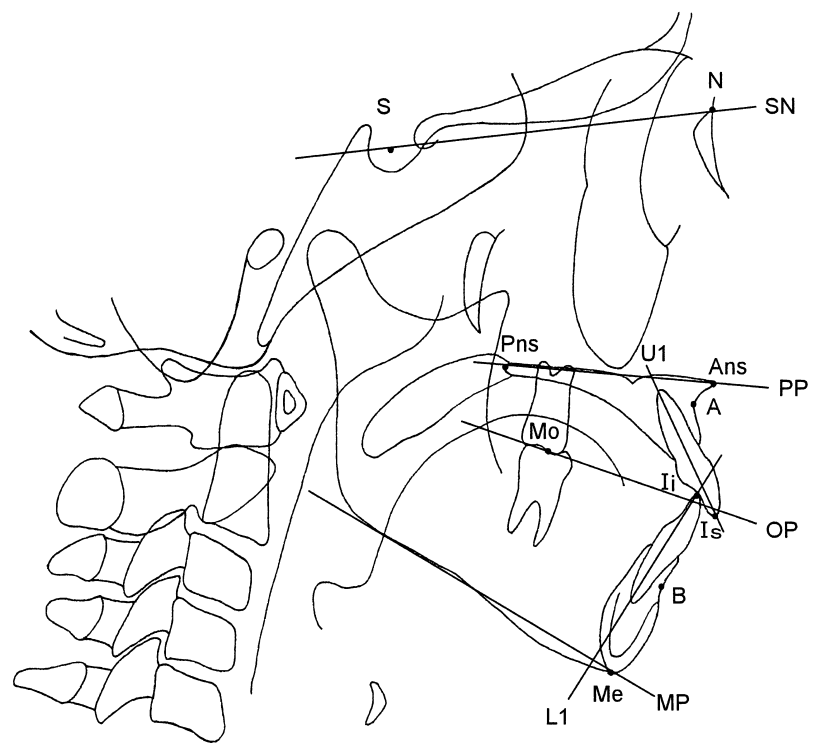

Fig. 2 Reference points and lines for angular measurements

at $\mathrm{T} 1, \mathrm{~T} 2$ and $\mathrm{T} 3$ in the treatment and control groups. Therefore, the following analyses were made on the pooled materials in the different groups.

Linear measurements at each period in the treatment and control groups are presented in Table 2. There were no statistically significant differences for any linear measurements at $\mathrm{T} 1$ or $\mathrm{T} 3$ between the treatment and control groups.

Angular measurements at each period in both groups and the reference sample are presented in Table 3. Except for the L1 to MP and U1 to L1 angles, there were no statistically significant differences for any measurements in the treatment and control groups compared with the reference sample. The L1 to MP angle at T1 and T2 in the treatment group, and at T1 and $\mathrm{T} 3$ in the control group was significantly smaller compared with the reference sample. The U1 to L1 angle at T1 and $\mathrm{T} 2$ in the treatment group was significantly larger than the reference sample. There were no significant differences for any angular measurements at $\mathrm{T} 1$ or T3 between both groups.

Cephalometric changes in linear measurements occurring during $\mathrm{T} 1-\mathrm{T} 2, \mathrm{~T} 2-\mathrm{T} 3$ and $\mathrm{T} 1-\mathrm{T} 3$ are presented in Table 4 . In the treatment group, there were no significant T1-T2 changes in any linear measurements. The dimensions of maxillary and mandibular bases, mandibular length, maxillary incisor, and maxillary and mandibular molars significantly increased, while the dimensions of molar relation and 
Table 2 Linear measurements at T1, T2 and T3 in the treatment and control groups

\begin{tabular}{|c|c|c|c|c|c|c|c|}
\hline \multirow{2}{*}{$\begin{array}{l}\text { Measurement } \\
(\mathrm{mm})\end{array}$} & \multicolumn{3}{|c|}{ Treatment group } & \multicolumn{2}{|c|}{ Control group } & \multicolumn{2}{|c|}{ Significance (TG-CG) } \\
\hline & $\mathrm{T} 1$ & $\mathrm{~T} 2$ & $\mathrm{~T} 3$ & $\mathrm{~T} 1$ & $\mathrm{~T} 3$ & $\mathrm{~T} 1$ & $\mathrm{~T} 3$ \\
\hline $\begin{array}{l}\text { 1. overjet } \\
\text { Is/OLp minus Ii/OLp }\end{array}$ & $2.9 \pm 1.6$ & $3.1 \pm 1.5$ & $3.8 \pm 0.9$ & $3.0 \pm 1.8$ & $3.7 \pm 1.9$ & NS & NS \\
\hline $\begin{array}{l}\text { 2. molar relation } \\
\mathrm{Ms} / \mathrm{OLp} \text { minus } \mathrm{Mi} / \mathrm{OLp}\end{array}$ & $-0.4 \pm 2.5$ & $-1.1 \pm 0.7$ & $-2.1 \pm 1.5$ & $0.0 \pm 1.3$ & $-1.3 \pm 1.8$ & NS & NS \\
\hline $\begin{array}{l}\text { 3. position of the maxillary base } \\
\text { Ans/OLp }\end{array}$ & $76.4 \pm 3.9$ & $77.6 \pm 3.9$ & $80.4 \pm 4.2$ & $75.9 \pm 3.1$ & $79.5 \pm 2.7$ & NS & NS \\
\hline $\begin{array}{l}\text { 4. position of the mandibular base } \\
\text { Pog/OLp }\end{array}$ & $80.0 \pm 4.3$ & $81.3 \pm 4.2$ & $86.5 \pm 4.4$ & $77.8 \pm 4.9$ & $83.5 \pm 4.5$ & NS & NS \\
\hline $\begin{array}{l}\text { 5. position of the condylar position } \\
\mathrm{Co} / \mathrm{OLp}\end{array}$ & $9.5 \pm 2.3$ & $10.3 \pm 2.8$ & $11.3 \pm 3.4$ & $9.5 \pm 2.2$ & $11.1 \pm 2.7$ & NS & NS \\
\hline $\begin{array}{l}\text { 6. mandibular length } \\
\mathrm{Pog} / \mathrm{OLp}+\mathrm{Co} / \mathrm{OLp}\end{array}$ & $89.5 \pm 4.1$ & $91.6 \pm 4.7$ & $97.8 \pm 5.5$ & $87.3 \pm 4.7$ & $94.7 \pm 4.6$ & NS & NS \\
\hline $\begin{array}{l}\text { 7. position of the maxillary central incisor } \\
\text { Is/OLp }\end{array}$ & $82.5 \pm 4.9$ & $83.5 \pm 4.2$ & $88.6 \pm 5.0$ & $82.4 \pm 3.6$ & $88.0 \pm 3.3$ & NS & NS \\
\hline $\begin{array}{l}\text { 8. position of the mandibular central incisor } \\
\text { Ii/OLp }\end{array}$ & $79.6 \pm 4.1$ & $80.4 \pm 4.3$ & $84.9 \pm 5.0$ & $78.0 \pm 3.8$ & $82.9 \pm 3.8$ & NS & NS \\
\hline $\begin{array}{l}\text { 9. position of the maxillary permanent first molar } \\
\text { Ms/OLp }\end{array}$ & $51.5 \pm 3.5$ & $53.0 \pm 3.5$ & $57.5 \pm 3.8$ & $51.7 \pm 2.7$ & $56.7 \pm 2.0$ & NS & NS \\
\hline $\begin{array}{l}\text { 10. position of the mandibular permanent first molar } \\
\mathrm{Mi} / \mathrm{OLp}\end{array}$ & $51.9 \pm 4.8$ & $54.1 \pm 3.5$ & $59.6 \pm 4.3$ & $51.7 \pm 2.8$ & $58.0 \pm 2.0$ & NS & NS \\
\hline
\end{tabular}

NS indicates no statistically significant difference

Table 3 Angular measurements at T1, T2 and T3 in the treatment and control groups

\begin{tabular}{|c|c|c|c|c|c|c|c|c|c|}
\hline \multirow{2}{*}{$\begin{array}{l}\text { Measurement } \\
\text { (in degrees) }\end{array}$} & \multicolumn{3}{|c|}{ Treatment group } & \multicolumn{2}{|c|}{ Control group } & \multicolumn{2}{|c|}{ Reference sample } & \multicolumn{2}{|c|}{ Significance (TG-CG) } \\
\hline & $\mathrm{T} 1$ & $\mathrm{~T} 2$ & $\mathrm{~T} 3$ & $\mathrm{~T} 1$ & $\mathrm{~T} 3$ & $\mathrm{~T} \cdot \mathrm{T} 2$ & $\mathrm{~T} 3$ & $\mathrm{~T} 1$ & $\mathrm{~T} 3$ \\
\hline SNA & $79.6 \pm 3.5$ & $79.4 \pm 2.9$ & $79.7 \pm 3.1$ & $79.7 \pm 3.9$ & $79.9 \pm 3.8$ & $80.5 \pm 3.4$ & $80.8 \pm 2.7$ & NS & NS \\
\hline SNB & $76.7 \pm 3.0$ & $76.5 \pm 2.5$ & $77.6 \pm 2.5$ & $76.8 \pm 3.5$ & $77.1 \pm 3.5$ & $76.8 \pm 2.9$ & $77.9 \pm 2.7$ & NS & NS \\
\hline ANB & $2.9 \pm 1.6$ & $3.0 \pm 1.7$ & $2.1 \pm 2.2$ & $2.9 \pm 1.9$ & $2.8 \pm 2.0$ & $3.7 \pm 1.5$ & $2.9 \pm 1.9$ & NS & NS \\
\hline MP to SN & $37.1 \pm 6.1$ & $37.2 \pm 4.8$ & $35.9 \pm 5.3$ & $39.1 \pm 5.3$ & $38.2 \pm 5.5$ & $36.7 \pm 4.5$ & $35.8 \pm 4.8$ & NS & NS \\
\hline $\mathrm{PP}$ to $\mathrm{SN}$ & $8.7 \pm 3.1$ & $8.9 \pm 3.0$ & $9.2 \pm 2.9$ & $8.7 \pm 3.2$ & $9.0 \pm 3.3$ & - & - & NS & NS \\
\hline PP to MP & $27.3 \pm 4.6$ & $28.3 \pm 5.1$ & $26.7 \pm 5.7$ & $30.4 \pm 5.4$ & $29.2 \pm 5.7$ & - & - & NS & NS \\
\hline $\mathrm{OP}$ to $\mathrm{SN}$ & $20.4 \pm 4.4$ & $19.7 \pm 3.8$ & $17.4 \pm 4.1$ & $21.0 \pm 3.3$ & $18.6 \pm 3.4$ & $21.5 \pm 3.0$ & $18.8 \pm 3.7$ & NS & NS \\
\hline $\mathrm{U} 1$ to $\mathrm{SN}$ & $103.9 \pm 5.4$ & $104.4 \pm 7.0$ & $108.9 \pm 5.3$ & $105.2 \pm 7.1$ & $109.1 \pm 7.4$ & $105.6 \pm 4.9$ & $106.7 \pm 5.9$ & NS & NS \\
\hline L1 to MP & $92.0 \pm 5.0^{* *}$ & $90.8 \pm 5.9^{* * *}$ & $93.3 \pm 5.1$ & $91.7 \pm 5.6^{* *}$ & $91.3 \pm 6.1^{* *}$ & $96.6 \pm 6.0$ & $96.1 \pm 5.2$ & NS & NS \\
\hline $\mathrm{U} 1$ to $\mathrm{L} 1$ & $126.9 \pm 6.6^{* * *}$ & $127.6 \pm 8.2^{* *}$ & $122.1 \pm 7.5$ & $123.9 \pm 9.4$ & $121.4 \pm 10.4$ & $121.1 \pm 7.4$ & $121.5 \pm 7.1$ & NS & NS \\
\hline
\end{tabular}

$* *: P<0.01, * * *: P<0.001$

NS indicates no statistically significant difference

mandibular incisor significantly decreased, during $\mathrm{T} 2-\mathrm{T} 3$ and $\mathrm{T} 1-\mathrm{T} 3$ in the treatment group, and during $\mathrm{T} 1-\mathrm{T} 3$ in the control group. There were no significant differences for the $\mathrm{T} 1-\mathrm{T} 2$ or $\mathrm{T} 1-\mathrm{T} 3$ changes in any linear measurements between both groups.
Cephalometric changes in angular measurements occurring during $\mathrm{T} 1-\mathrm{T} 2, \mathrm{~T} 2-\mathrm{T} 3$ and $\mathrm{T} 1-\mathrm{T} 3$ are presented in Table 5. There were no significant changes in any angular measurements during T1$\mathrm{T} 2$ in the treatment group. The $\mathrm{U} 1$ to $\mathrm{SN}$ angle significantly increased during $\mathrm{T} 2-\mathrm{T} 3$ and $\mathrm{T} 1-\mathrm{T} 3$, 
Table 4 Changes in linear measurements during T1-T2, T2-T3 and T1-T3 in the treatment and control groups

\begin{tabular}{|c|c|c|c|c|c|c|c|}
\hline \multirow{2}{*}{$\begin{array}{l}\text { Measurement } \\
\qquad(\mathrm{mm})\end{array}$} & \multicolumn{3}{|c|}{ Treatment group } & \multicolumn{2}{|c|}{ Control group } & \multicolumn{2}{|c|}{ Significance (TG-CG) } \\
\hline & $\mathrm{T} 1-\mathrm{T} 2$ & $\mathrm{~T} 2-\mathrm{T} 3$ & $\mathrm{~T} 1-\mathrm{T} 3$ & interpolated $\mathrm{T} 1-\mathrm{T} 2$ & $\mathrm{~T} 1-\mathrm{T} 3$ & $\mathrm{~T} 1-\mathrm{T} 2$ & $\mathrm{~T} 1-\mathrm{T} 3$ \\
\hline $\begin{array}{l}\text { 1. overjet } \\
\text { Is/OLp (d) minus Ii/OLp (d) }\end{array}$ & $0.2 \pm 2.2$ & $0.7 \pm 1.6$ & $0.9 \pm 1.5$ & $0.3 \pm 0.8$ & $0.7 \pm 1.5$ & NS & NS \\
\hline $\begin{array}{l}\text { 2. molar relation } \\
\mathrm{Ms} / \mathrm{OLp}(\mathrm{d}) \text { minus Mi/OLp (d) }\end{array}$ & $-0.7 \pm 2.6$ & $-1.0 \pm 1.6$ & $-1.7 \pm 2.9$ & $-0.6 \pm 0.7$ & $-1.3 \pm 1.8$ & NS & NS \\
\hline $\begin{array}{l}\text { 3. position of the maxillary base } \\
\text { Ans/OLp (d) }\end{array}$ & $1.2 \pm 1.1$ & $2.8 \pm 1.6^{*}$ & $4.0 \pm 2.1^{* *}$ & $1.3 \pm 0.8$ & $3.6 \pm 2.1^{* *}$ & NS & NS \\
\hline $\begin{array}{l}\text { 4. position of the mandibular base } \\
\text { Pog/OLp (d) }\end{array}$ & $1.3 \pm 2.1$ & $5.2 \pm 2.2^{* *}$ & $6.5 \pm 2.6^{* * *}$ & $2.0 \pm 0.8$ & $5.8 \pm 2.3^{* *}$ & NS & NS \\
\hline $\begin{array}{l}\text { 5. position of the condylar position } \\
\text { Co/OLp (d) }\end{array}$ & $0.7 \pm 1.9$ & $1.1 \pm 1.9$ & $1.8 \pm 2.4$ & $0.5 \pm 0.8$ & $1.6 \pm 1.9$ & NS & NS \\
\hline $\begin{array}{l}\text { 6. mandibular length } \\
\text { Pog/OLp (d) + Co/OLp (d) }\end{array}$ & $2.0 \pm 2.9$ & $6.2 \pm 3.3^{* *}$ & $8.3 \pm 3.6^{* * *}$ & $2.6 \pm 1.0$ & $7.4 \pm 3.1^{* * *}$ & NS & NS \\
\hline $\begin{array}{l}\text { 11. maxillary incisor } \\
\text { Is/OLp (d) minus Ans /OLp (d) }\end{array}$ & $-0.2 \pm 2.4$ & $2.3 \pm 1.7^{* *}$ & $2.1 \pm 2.1^{* *}$ & $0.8 \pm 1.0$ & $2.1 \pm 2.2^{* * *}$ & NS & NS \\
\hline $\begin{array}{l}\text { 12. mandibular incisor } \\
\text { Ii/OLp (d) minus Pog/OLp (d) }\end{array}$ & $-0.5 \pm 1.4$ & $-0.7 \pm 1.5^{* *}$ & $-1.2 \pm 1.7^{* *}$ & $-0.3 \pm 0.7$ & $-0.8 \pm 1.6^{* * *}$ & NS & NS \\
\hline $\begin{array}{l}\text { 13. maxillary molar } \\
\text { Ms/OLp (d) minus Ans/OLp (d) }\end{array}$ & $0.3 \pm 1.3$ & $1.7 \pm 1.5^{* *}$ & $1.9 \pm 2.2^{* * *}$ & $0.4 \pm 0.6$ & $1.4 \pm 1.8^{* * *}$ & NS & NS \\
\hline $\begin{array}{l}\text { 14. mandibular molar } \\
\mathrm{Mi} / \mathrm{OLp}(\mathrm{d}) \text { minus Pog/OLp (d) }\end{array}$ & $0.8 \pm 2.6$ & $0.3 \pm 1.4^{* * *}$ & $1.2 \pm 3.1^{* * *}$ & $0.2 \pm 0.6$ & $0.5 \pm 1.5^{* * *}$ & NS & NS \\
\hline
\end{tabular}

*: $P<0.05$, **: $P<0.01$, ***: $P<0.001$

NS indicates no statistically significant difference

Table 5 Changes in angular measurements during T1-T2, T2-T3 and T1-T3 in the treatment and control groups

\begin{tabular}{|c|c|c|c|c|c|}
\hline \multirow{2}{*}{$\begin{array}{l}\text { Measurement } \\
\text { (in degrees) }\end{array}$} & \multicolumn{3}{|c|}{ Treatment group } & \multirow{2}{*}{$\begin{array}{c}\text { Control group } \\
\text { T1-T3 }\end{array}$} & \multirow{2}{*}{$\frac{\text { Significance }(\mathrm{TG}-\mathrm{CG})}{\mathrm{T} 1-\mathrm{T} 3}$} \\
\hline & $\mathrm{T} 1-\mathrm{T} 2$ & $\mathrm{~T} 2-\mathrm{T} 3$ & $\mathrm{~T} 1-\mathrm{T} 3$ & & \\
\hline SNA & $-0.2 \pm 1.7$ & $0.3 \pm 1.4$ & $0.1 \pm 2.1$ & $0.2 \pm 1.7$ & NS \\
\hline SNB & $-0.2 \pm 1.8$ & $1.0 \pm 1.3$ & $0.8 \pm 1.6$ & $0.3 \pm 1.2$ & NS \\
\hline ANB & $0.1 \pm 1.2$ & $-0.9 \pm 1.3$ & $-0.8 \pm 1.5$ & $-0.1 \pm 1.7$ & NS \\
\hline $\mathrm{MP}$ to $\mathrm{SN}$ & $0.1 \pm 3.6$ & $-1.3 \pm 1.5$ & $-1.2 \pm 3.9$ & $-0.9 \pm 1.4$ & NS \\
\hline $\mathrm{PP}$ to $\mathrm{SN}$ & $0.2 \pm 1.4$ & $0.2 \pm 1.3$ & $0.5 \pm 1.9$ & $0.3 \pm 3.3$ & NS \\
\hline PP to MP & $1.0 \pm 1.4$ & $-1.6 \pm 1.8$ & $-0.6 \pm 2.4$ & $-1.2 \pm 2.0$ & NS \\
\hline OP to $\mathrm{SN}$ & $-0.7 \pm 2.4$ & $-2.4 \pm 1.9$ & $-3.0 \pm 2.0$ & $-2.4 \pm 2.5$ & NS \\
\hline $\mathrm{U} 1$ to $\mathrm{SN}$ & $0.5 \pm 5.8$ & $4.4 \pm 3 .{ }^{*}$ & $4.9 \pm 5.0^{*}$ & $3.9 \pm 4.1$ & NS \\
\hline L1 to MP & $-1.2 \pm 4.1$ & $2.5 \pm 4.4$ & $1.3 \pm 3.8$ & $-0.3 \pm 4.5$ & NS \\
\hline $\mathrm{U} 1$ to $\mathrm{L} 1$ & $0.7 \pm 6.6$ & $-5.6 \pm 6.0^{*}$ & $-4.9 \pm 5.5$ & $-2.4 \pm 6.5$ & NS \\
\hline
\end{tabular}

$*: P<0.05$

NS indicates no statistically significant difference

while the U1 to L1 angle significantly decreased during T2-T3 in the treatment group. The OP to SN angle significantly decreased in the control group. There were no significant differences for the T1-T3 change in any angular measurements between both groups.

\section{Discussion}

The $2 \times 4$ mechanotherapy is one of the most commonly practiced procedures today for early treatment of maxillary incisor crowding. Previous studies on crowding of teeth have been conducted, 
focusing on craniofacial morphology in relation to mandibular incisor crowding ${ }^{1-5,8}$. This criteria is based on the Gianelly's finding that mandibular arch conditions generally dictate the strategy for maxillary arch treatment ${ }^{1,3)}$. These studies have demonstrated that the incisor crowding adds to the anteroposterior skeletal and dental discrepancies, which include the retrusion of the mandible and mandibular incisors. However, changes in these anteroposterior discrepancies after early treatment of maxillary incisor crowding have not been shown in the past literatures. The Pancherz's reference system $^{10)}$ has been used to evaluate the treatment outcome of Class II correction in the incisor and molar segments with the Herbst appliance ${ }^{10)}$, headgear ${ }^{13)}$ and bionator ${ }^{14)}$. In the present study, this reference system for linear measurements of anteroposterior skeletal and dental changes was adopted mainly for two reasons ${ }^{10)}$ : First, the reference systems was close to the problem area; second, all measurements were made by the use of the same reference line (OLp), which made it possible to evaluate the relationship between skeletal and dental changes in different jaws.

No statistically significant differences were found for any linear and angular measurements at T1 between the treatment and control groups, which confirmed the adequate selection of subjects in each group. The most interesting characteristic at $\mathrm{T} 1$ in both groups was the large retroclination of the mandibular incisors compared with the reference sample, as had been observed by Sanin and Savara ${ }^{4}$, and Leighton and Hunter ${ }^{8)}$. Björk ${ }^{15)}$ and Lundström ${ }^{16)}$ showed that lingually inclined mandibular incisors was associated with predominant horizontal growth of mandible. The SNB angle at T1 in each group was, however, not large enough to indicate a prognathic mandible. Almost all the subjects in our study had maxillary lateral incisors displaced lingually more or less. In the subjects with the average vertical and horizontal mandibular growth, the retroclination of mandibular incisors may have been due to compensatory reaction to the lingual movement of the maxillary central incisor tips in order to maintain incisal contact (Table 4). This observation is in agreement with the finding of Norderval et al. ${ }^{5}$, that the mandibular incisor crowding is reflected by the maxillary incisor crowding, but in conflict with Gianelly's finding mentioned above ${ }^{1,3)}$. The interincisal angle in both groups was larger, which was only significantly large in the treatment group, compared with the reference sample. Apparently, the obtuseness of the interincisal angle resulted from the retroclination of mandibular incisors because the $\mathrm{U} 1$ to $\mathrm{SN}$ angle was about average.

The changes in measurements during the T1-T2 period in the treatment group as shown in Table 4 were due to a combination of growth and treatment changes. The maxillary and mandibular bases grew forward by $1.2 \mathrm{~mm}$ and $1.3 \mathrm{~mm}$, respectively. Maxillary and mandibular incisors within maxilla and mandible moved distally by $0.2 \mathrm{~mm}$ and $0.5 \mathrm{~mm}$ respectively, while maxillary and mandibular molars moved mesially $0.3 \mathrm{~mm}$ and $0.8 \mathrm{~mm}$, respectively. The resolution of maxillary incisor crowding brought about the retrusive movement of maxillary central incisor tips, which was quite different from the T2-T3 and T1-T3 changes in the treatment groups, and the interpolated $\mathrm{T} 1-\mathrm{T} 2$ and $\mathrm{T} 1-\mathrm{T} 3$ changes in the control group. The backward movement of maxillary central incisors might be caused by the reciprocal effect of the forward movement of maxillary lateral incisors. The elongation of maxillary molars accompanied the $2 \times 4$ mechanotherapy and growth as evidenced by the decrement of the OP to $\mathrm{SN}$ angle (Table 5). Contrary to our expectation, the resolution of maxillary incisor crowding during T1-T2 produced the retroclination of mandibular incisors despite the fact that occlusion was unlocked in incisor segment. The forward movement of maxillary lateral incisors and the elongation of maxillary molars must have stimulated the forward growth of the mandibular base to become larger enough to produce the retroclination of mandibular incisors relative to changes in the dimension of incisors within the mandible (Tables 4 and 5).

At the completion of the overall treatment/ observation period, the L1 to MP angle was significantly small in the control group but not so significantly small in the treatment group, compared with the reference sample (Table 3). Our finding that the retroclination of mandibular incisors was significantly large in the control group supposed the results of the studies published by Sanin and Savara $^{4}$, and Leighton and Hunter ${ }^{8}$. They reported that the degree of retroclination of mandibular incisors increased with growth. There were no statistically significant differences for the T1-T3 changes in any linear and angular measurements between the treatment and control groups (Tables 4 and 5). However, one characteristic finding was that the changes in the L1 to MP angle during T1-T3 showed positive values in the treatment group and 
negative values in the control group (Table 5). Presumably the increment of the L1 to MP angle must have been produced by the release from the occlusal lock in the incisor segment by the alignment of maxillary incisors with the $2 \times 4$ mechanotherapy, resulting in the significant increment of the U1 to $\mathrm{SN}$ angle. These results suggested that the resolution of maxillary incisor crowding mostly produce the anteroposterior dental effects, and that its effect on the correction of the retroclination of mandibular incisors which was observed at the start of the $2 \times 4$ mechanotherapy was not so significant.

\section{References}

1) Gianelly, A.A.: Crowding: timing of treatment. Angle Orthod 64: 415-418, 1994.

2) Brennan, M.M. and Gianelly, A.A.: The use of the lingual arch in the mixed dentition to resolve incisor crowding. Am J Orthod Dentofacial Orthop 117: 8185, 2000.

3) Gianelly, A.A.: Treatment of crowding in the mixed dentition. Am J Orthod Dentofacial Orthop 121: 569-571, 2002.

4) Sanin, C. and Savara, B.: Factors that affect the alignment of the mandibular incisors: A longitudinal study. Am J Orthod 64: 248-257, 1973.

5) Norderval, K., Wisth, P.J. and Böe, O.E.: Mandibular anterior crowding in relation to tooth size and craniofacial morphology. Scand J Dent Res 83: 267-273, 1975.

6) Sakuda, M., Kuroda, Y., Wada, K. and Matsumoto, M.: Changes in crowding of teeth during adolescence and their relation to the growth of the facial skeleton. Trans Eur Orthod Soc., London, 1977, pp.93-104.

7) Rönnerman, A. and Thilander, B.: Facial and dental arch morphology in children with and without early loss of deciduous molars. Am J Orthod 73: 47-58, 1978.

8) Leighton, B.C. and Hunter, W.S.: Relationship between lower arch spacing/crowding and facial height and depth. Am J Orthod 82: 418-425, 1982.

9) Berg, R.: Crowding of the dental arches: a longitudinal study of the age period between 6 and 12 years. Eur J Orthod 8: 43-49, 1986.

10) Pancherz, H.: The mechanism of class II correction in Herbst appliance treatment. Am J Orthod 82: 104113, 1982.

11) Japanese society of pediatric dentistry: A study on the cephalometric standards of Japanese children. Jpn J Ped Dent 33: 659-696, 1995. (in Japanese)

12) Dahlberg, G.: Statistical methods for medical and biological students. George Allen and Unwin Ltd., London, 1940, pp. 122-132.

13) Bendeus, M., Hägg, U. and Rabie, B.: Growth and treatment changes in patients treated with a headgearactivator appliance. Am J Orthod Dentofacial Orthop 121: 376-384, 2002.

14) Faltin, K. Jr., Faltin, R.M., Baccetti, T., Franchi, L., Ghiozzi, B. and McNamara, J.A. Jr.: Long-term effectiveness and treatment timing for bionator therapy. Angle Orthod 73: 221-230, 2003.

15) Björk, A.: Variations in the growth pattern of human mandible: Longitudinal radiographic study by the implant method. J Dent Res 42: 400-411, 1963.

16) Lundström, A.: A study of the correlation between mandibular growth direction and changes in incisor inclination, overjet, overbite and crowding. Trans Eur Orthod Soc., London, 1975, pp. 131-140. 